\title{
PILOT STUDY IN THE RESEARCH PROCEDURE
}

\author{
Henryk DŹWIGOŁ \\ Silesian University of Technology, Faculty of Organisation and Management, Zabrze; \\ henryk.dzwigol@poczta.fm, ORCID: 0000-0002-2005-0078
}

Introduction/background: The intent of the paper was to verify the hypothesis:

- H0 - Pilot study is an integral part of any research process and directs the research process.

- H1 - Pilot study is not an integral part of any research process and does not direct the research process.

Aim of the paper: The aim of the paper is to verify whether a pilot study is an integral part of any research process and whether it directs research processes.

Materials and methods: In order to verify the hypothesis, a quantitative survey (questionnaire) was conducted, which was addressed to a group of management science theoreticians (401 representatives).

Results and conclusions: The results obtained revealed that:

- $86 \%$ of the surveyed scientists, specialising in management science, believe that pilot studies direct the research process,

- $88 \%$ of all scientists specialising in management science believe that pilot studies have an impact on the course of the research process,

- $70 \%$ of all management scientists believe that pilot studies are an integral part of any research process.

Thus, hypothesis H1 was rejected.

Of key importance, from the point of view of the development of this science, are the needs to develop principles for the application of the methods that make up the pragmatic methodology, and to disseminate methodological paradigms identified in particular in the approach of the contemporary methodology of management sciences.

Keywords: research process, pilot studies, research methodology, management science.

\section{Introduction}

Research is a complex process leading to finding solutions to a specific problem (Apukem, 2017; Park and Park, 2016). Its result may assume a purely cognitive form (Bryman, 2006), but it may also be implemented on the basis of specific practical objectives (Hessen, 2019; Vaivio and Sirén, 2010). Science focuses on exploring groups of subjects, multiple facts and processes, as well as frequently recurring phenomena (Dźwigoł et al., 2019). Hence, researchers should 
not pay all their attention to unique phenomena or single entities (Thomas, 2017). Science strives for generalizations that allow for the development of a theory exempt from individual, personal characteristics that are unnecessary to explore the essence of the phenomenon in question (Hair et al., 2019). 'In the case of the generalizing approach, a certain object or set of objects is worth knowing and therefore, in so far as it represents a certain broader category of phenomena or objects of a certain type (much broader of its own scope), its cognition is the proper objective of the research procedure' (Nowak, 1965). According to B. Zeigarnik 'only generalised thinking, thinking with concepts fully reflects the reality' (Zeigarnik, 1980).

A theory is a cornerstone of any science. It is viewed as a description of reality, and in particular a description of more or less regularly repeated, stated or hypothetically assumed relationships between states and changes in circumstances, simplified by omitting those details which, for some reasons, are considered irrelevant in a given case (Zielniewski, 1969). Scientific research aims to answer questions that do not yet have this answer (Ferran-Ferrer et al., 2017). The degree of the work's originality or its novelty varies (Williman, 2017). Some researchers understand, by the criterion of novelty, the originality of the work (Apuke, 2017; Hammarberg et al., 2016). Scientific research should primarily involve the pursuit of an explanation for a given phenomenon (Joslin and Müller, 2016), which, at a later stage, leads to the discovery of a new scientific truth (Dźwigol, 2018). In the management science, combined with the scientific research, the aim is to explore new regularities, methods or ways to increase the effectiveness of management. Research can indeed contribute to the discovery of a new truth, but it can also lead to the modification of a known state or process, or the improvement of what is already there (Park and Park, 2016). E. Wilson rightly points out that the laws of science are a growing and ever-changing organism, but that change is generally evolutionary in nature and consists much more of modifications, improvements, and extensions than of the ruthless rejection of old things (Wilson, 1964).

Far from the truth is the claim that every question left unanswered so far should be answered. This means that not every phenomenon that has not yet been clarified can be the subject of scientific research. Research should not be started if the questions asked (unexplained phenomena) are socially meaningless or even too simple to be the subject of research. Concerns about the exhaustion of possible research topics are hardly justified. According to J. Zieleniewski, the number of problems requiring solution is not decreasing. On the contrary, the more specialists in a given field expand their knowledge, the deeper they penetrate its intricacies, the more questions appear and the more issues open up for research (Zieleniewski, 1969). Still, the problems faced by contemporary researchers are increasingly complex, multidimensional and interdisciplinary, making them more difficult to solve (Tonidandel et al. 2016).

In order to avoid confusion with an erroneously devised data collection tool, a pilot study should be carried out. The pilot studies, otherwise known as preliminary studies, are carried out prior to the basic (core) studies when a problem, process, phenomenon or mechanism specific 
to a given community, location, object or society is scarcely studied - that is, very little is known about it (mfiles.pl/en). Such research is often conducted on a small scale and constitutes the first contact with the analysed reality.

The pilot study allows gathering preliminary knowledge about the studied phenomenon (Mutz and Müller, 2016). The main purpose of such study is to collect information (implicitly incomplete, because only core studies allow collecting all the necessary data to verify the theses adopted in the work) to verify the chosen direction, formulate assumptions for the work, or check the correctness of the developed questionnaire - in the case of surveys (Kaur et al., 2017). Pilot studies also serve to check the usefulness of the adopted research methods and tools to investigate a given problem (Thomas, 2017). By conducting preliminary research, the researcher gains confirmation or negation of the previously accepted connections between the studied phenomena.

Furthermore, a pilot study also allows for the selection of the information collected (Morris and Rosenbloom, 2017). This results in the rejection of information that is irrelevant to the problem under investigation or that is not present in the environment or population. Apart from checking the correctness of the developed questionnaire, it is also possible to obtain knowledge about the duration of basic research or a reliable random sample size (Mutz and Müller, 2016).

A pilot study appears to be necessary if (Dźwigol, 2018):

- the field of study is being explored for the first time,

- completely new methods and tools are used in research,

- it is likely that the assumptions made in the studies cannot be maintained.

\section{Research method}

Conclusions derived from the analysis of national and foreign literature on the research process indicate the need to diagnose the impact of pilot studies on the quality of the research process in management science. Thus, the research problem is formulated as follows: Does the pilot study direct research processes?

Therefore, the following research questions were posed in the article:

Q1 Should the researcher provide methods for the implementation of effective solution patterns?

Q2 Does the pilot study direct research processes?

Q3 Does the pilot study affect research processes?

Q4 Is a pilot study an integral part of any research process?

Providing answers to such research questions will allow verifying the following hypothesis: 'Pilot studies are an integral part of any research process and direct the research process.' 
The research was conducted on the basis of an anonymous questionnaire in two formats. One of them is a paper form that was distributed among respondents during scientific conferences on management science, and the other is an electronic form, based on an e-mail database. The research was conducted from October 2016 to April 2018.

The respondents answered questions that were grouped into three parts. The first part was aimed at collecting opinions about the importance of approaches, processes, methods and techniques in a research process within the scope of management science (5 questions). The second part consisted of questions related to the problem of the improvement of a research process (33 questions). The third part contained demographics (3 questions). The structure of the questionnaire involved open, rank questions, and questions based on the 5-point Likert scale.

The target group was 401 management science theoreticians.

\section{Research findings}

\section{Should the researcher provide methods for the implementation of effective solution patterns?}

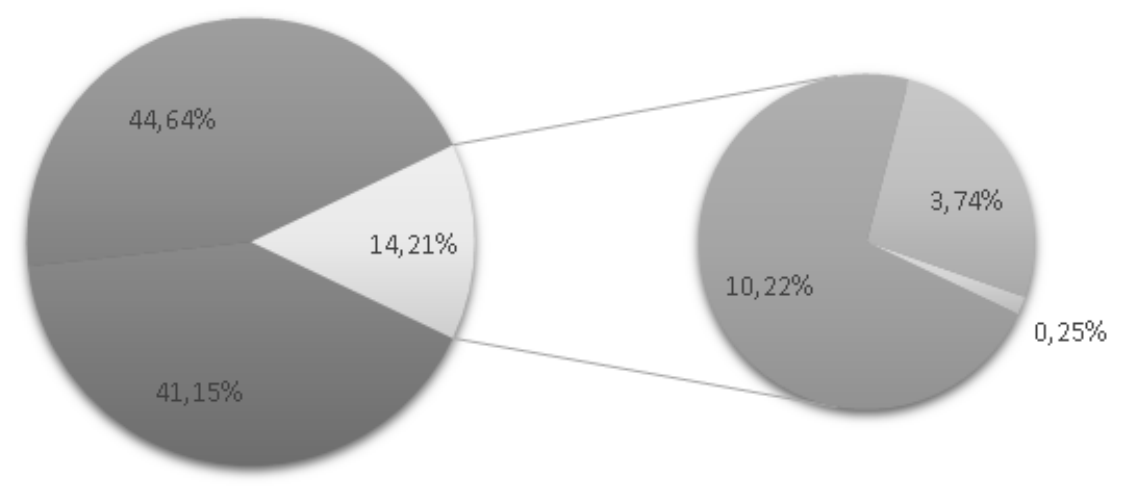

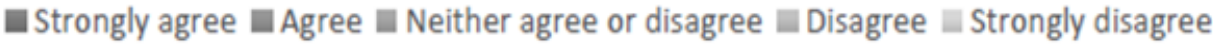

Figure 1. Research findings: Q1. Should the researcher provide methods for the implementation of effective solution patterns? The Author's own research.

Assuming that the purpose of the discipline of management science is to serve the practice of economic and social life through providing models of effective solutions in the area of organisation and management, as well as providing methods of implementation of these models, it should be noted that science and related research works are gradually becoming more and more connected with economic practice than before (Hair et al., 2019). 
Therefore, the key to the development of this science is the need to elaborate the principles of application of the methods that constitute the pragmatic methodology, and to disseminate methodological paradigms identified especially in the approach of contemporary methodology of management science, as doing so would make it easier for both theoreticians and practitioners to choose a specific research method more easily and efficiently (Bryman, 2006; Vaivio and Sirén, 2010).

\section{Does the pilot study direct research processes?}

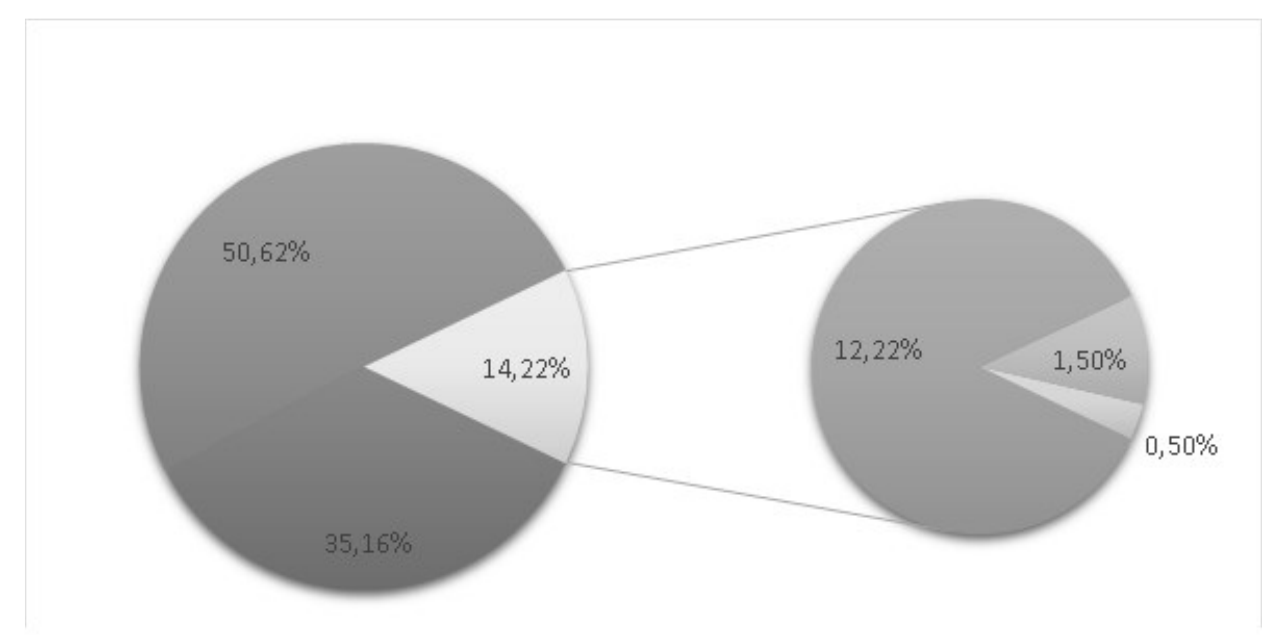

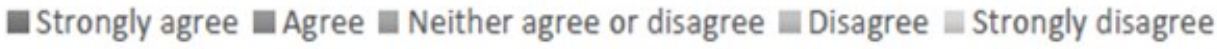

Figure 2. Research findings: Q2. Does the pilot study direct research processes? The Author's own research.

When analysing the results obtained, the vast majority of the respondents $(85.78 \%)$ believe that the pilot studies steer the research process. Only eight respondents $(2 \%)$ believe that pilot study does not, or rather does not, direct the research process. The pilot study is carried out in order to test whether the study will be appropriate and will yield specific data. According to Gruszczyński (1999), the tasks of the pilot study include:

- verification of a research problem, including answers to the following questions: does the research problem occur in the community under investigation, has it been properly operationalised, do the indicators fulfil their functions, do the concepts have the same empirical meaning, can the research problem be solved with such a research technique;

- verification of the research tool: evaluation of the questionnaire and individual questions for establishing contact between the researcher and the examined person, evaluation of the questions in terms of their usefulness for solving the problem, checking whether the questions are adjusted to the capabilities of the examined person, checking the degree of accuracy and relevance of the obtained answers, evaluation of the comprehensibility of a question and the adequacy of the criteria (the statements contained in the answer 'Others. Which? ...' are helpful), determining whether the open questions used in the questionnaire could be replaced by closed ones, analysis of the questions and answers in terms of their completeness, checking how many questions remain unanswered; 
- determining the organisational and technical aspects of the study: checking the time of research implementation (including arrival, contact with respondents, filling in questionnaires), verification of the survey, estimation of the list of inaccessible entities, checking the ways of reaching the respondents and places where the survey was conducted, determining the costs, checking the network of interviewers;

- development of the collected empirical material: preparation of code instructions, decisions related to tables of results, coefficients and statistical tests.

During the pilot study, not only the test procedure, sample selection, specific questions, but also the answers given by the respondents should be verified, as a seemingly uncomplicated question will provide answers that are radically different, proving that everyone understood it differently. It is also crucial to test the work of the interviewers, whether they are able to properly select their respondents (whether doing so is not too complicated and timeconsuming), whether they can complete the questionnaire, etc.

\section{Does the pilot study affect research processes?}

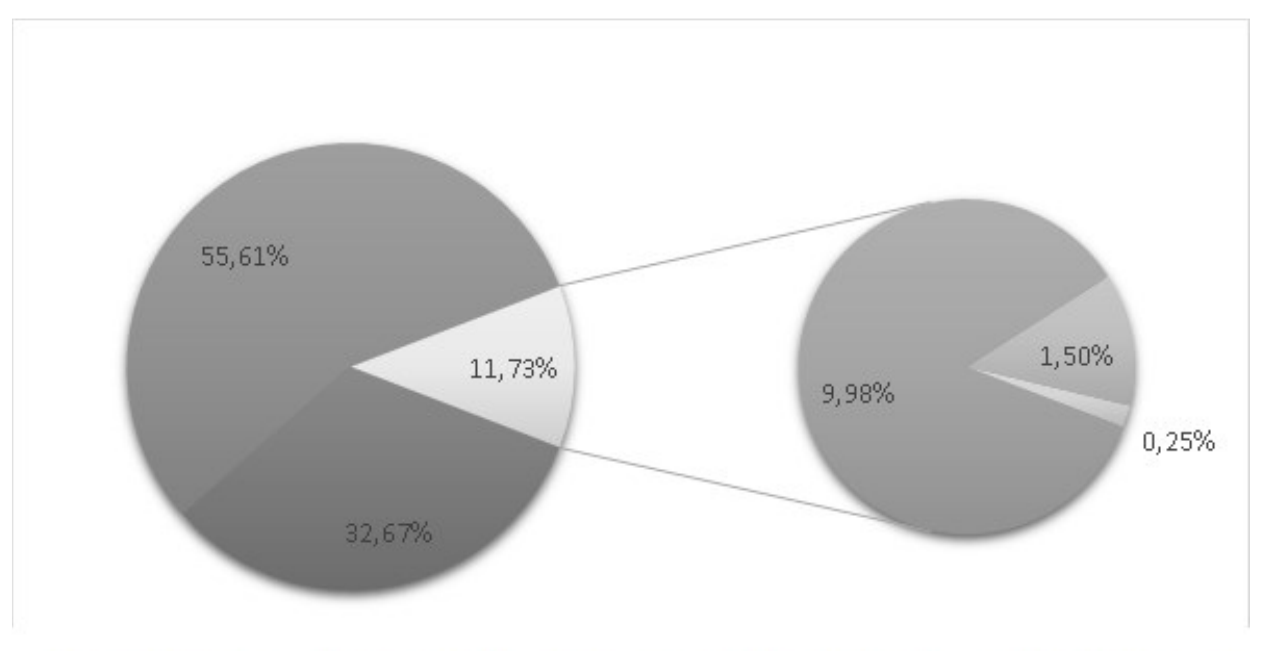

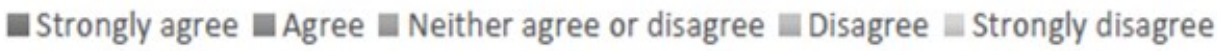

Figure 3. Research findings: Q3. Does the pilot study affect research processes? The Author's own research.

When analysing the results obtained, the vast majority of respondents believe that the pilot study has an impact on the research process.

The main problem that researchers in preparing a pilot study have to face is, therefore, whether to restrict themselves to carrying out the study in the same way as the proper study is run, or to extend the scope and collect additional opinions. On the one hand, the pilot study should be as similar as possible to the basic study, but on the other hand, it is designed to supply all and any information to help improve the said study. It is not easy to solve the problem and it is usually a matter of individual concern for each researcher.

It is assumed that the population for the pilot study should be $5 \%$ of the main population to be surveyed. If the target population is scarce, another group can be used for piloting, i.e. a group that is somehow similar to it and represents an alternative for it. It must be 
underlined that the respondents who took part in the pilot study should not participate in the basic (core) study.

Is a pilot study an integral part of any research process?

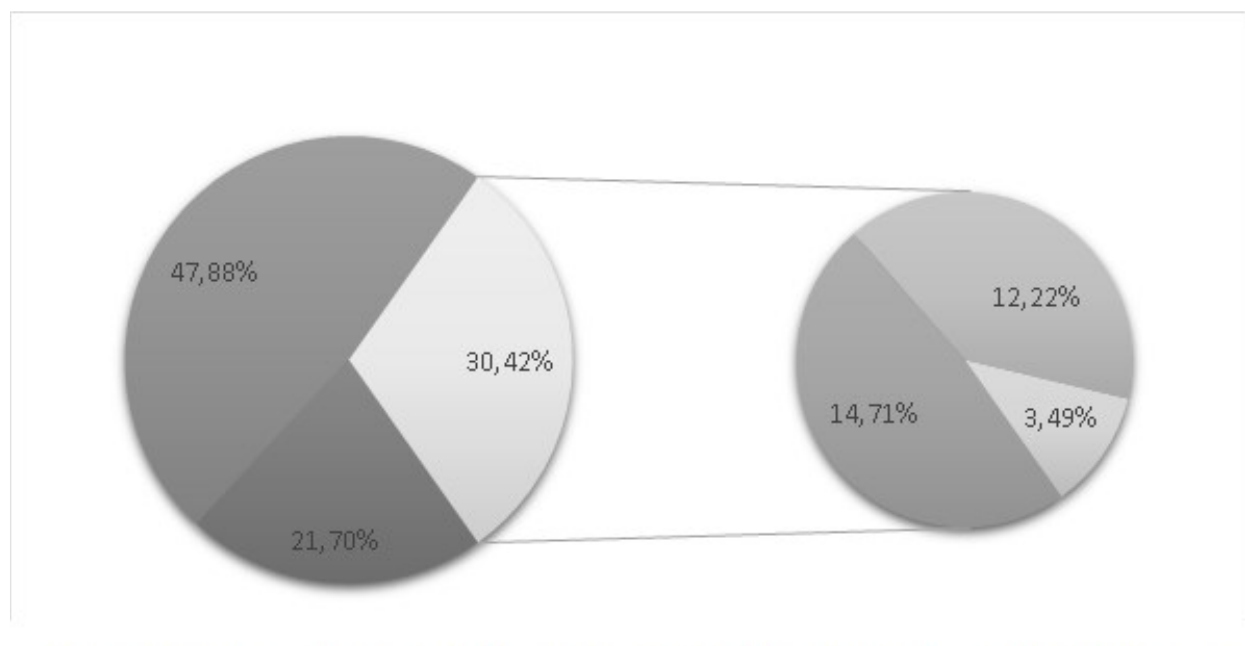

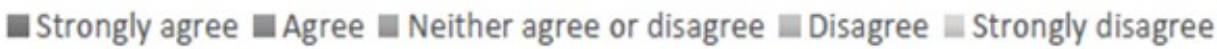

Figure 4. Research findings: Q4. Is a pilot study an integral part of any research process? The Author's own research.

During the pilot study, beyond the test procedure, sample selection and specific questions, the answers given by the respondents are reviewed. In certain situations, a seemingly uncomplicated question will generate radically different answers. This suggests that the respondents understood it differently. A pilot study enables the testing of the work of the interviewers, whether they aptly selected their respondents (whether doing so is not too complicated and time-consuming), whether they can complete the questionnaire, etc. Taking into account the above statements and the achieved research findings, in which a significant proportion of respondents believe that a pilot study is an integral part of any research process, it can be argued that, when structuring the research methodology, each researcher should contemplate carrying out pilot studies to identify the correctness of the selected methods, techniques, procedures, but also the questions posed, and to verify inferencing.

\section{Summary and research findings}

The aim of the paper was to verify the hypothesis:

- $H_{0}$ - Pilot study is an integral part of any research process and directs the research process.

- $H_{1}-$ Pilot study is not an integral part of any research process and does not direct the research process. 
In conclusion, the pilot study not only directs the research process or has a clear impact on it, but it is also an integral part of it. During the pilot study, not only the research procedure, sample selection, specific questions, but also answers given by the respondents are checked. The researcher should reflect on conducting pilot studies in order to identify the correctness of the selected methods, techniques, procedures, but also the posed questions, and to verify inferencing.

This is corroborated by the results obtained, in which:

- $86 \%$ of the surveyed scientists specialising in management science, believe that pilot studies direct the research process,

- $88 \%$ of all surveyed scientists specialising in management science believe that pilot studies have an impact on the course of the research process.

- $\quad 70 \%$ of all surveyed management scientists believe that pilot studies are an integral part of any research process.

Thus, the hypothesis $\mathrm{H}_{1}$ was rejected.

Of key importance, from the point of view of the development of this science, are the needs to develop principles for the application of the methods that make up the pragmatic methodology, as well as to disseminate methodological paradigms identified in particular in the approach of the contemporary methodology of management sciences.

\section{References}

1. Apuke O.D. (2017). Quantitative Research Methods: A Synopsis Approach. Arabian Journal of Business and Management Review, 6(10), DOI: 10.12816/0040336.

2. Bryman, A. (2006) Integrating quantitative and qualitative research: How is it done? Qualitative Research, 6(1), 3-37, https://doi.org/10.1177/1468794106058877.

3. Dźwigoł, H. (2018). Współczesne procesy badawcze $w$ naukach o zarzadzaniu. Uwarunkowania metodyczne i metodologiczne. Warszawa: PWN.

4. Dzwigol, H., Aleinikova, O., Umanska, Y., Shmygol, N., \& Pushak, Y. (2019). An Entrepreneurship Model for Assessing the Investment Attractiveness of Regions. Journal of Entrepreneurship Education, 22(SI1), 1-7.

5. Dźwigoł, H., Dźwigoł-Barosz, M., Zhyvko, Z., Miśkiewicz, R., Pushak, H. (2019). Evaluation of the energy security as a component of national security of the country. Journal of Security and Sustainability Issues, 8(3), 307-317. http://doi.org/10.9770/ jssi.2019.8.3(2).

6. Ferran-Ferrer, N., Guallar, J., Abadal, E. and Server, A. (2017). Research methods and techniques in Spanish library and information science journals (2012-2014). Information Research, 22(1). 
7. Gruszczyński, L.A. (1999). Kwestionariusze w socjologii: budowa narzędzi do badań surveyowych. Katowice: Uniwersytet Śląski.

8. Hair, J.F., Page, M., and Brunsveld, N. (2019). Essentials of Business Research Methods. 4th Edition. New York: Routledge, https://doi.org/10.4324/9780429203374.

9. Hammarberg, K., Kirkman, M., and de Lacey, S. (2016). Qualitative research methods: when to use them and how to judge them. Human Reproduction, 31(3), 498-501, https://doi.org/10.1093/humrep/dev334.

10. Hessen, R., Bright, L.K., and Zucker A. (2019). Vindicating methodological triangulation. Synthese, 196(8), 3067-3081, https://doi.org/10.1007/s11229-016-1294-7.

11. Joslin, R., and Müller, R. (2016). Identifying interesting project phenomena using philosophical and methodological triangulation. International Journal of Project Management, 34(6), 1043-1056, https://doi.org/10.1016/j.ijproman.2016.05.005.

12. Kaur, N., Figueiredo, S., Bouchard, V., Moriello, C., and Mayo, N. (2017). Where have all the pilot studies gone? A follow-up on 30 years of pilot studies in Clinical Rehabilitation. Clinical Rehabilitation, 31(9), 1238-1248. https://doi.org/10.1177/ 0269215517692129.

13. Morris, N.S., and Rosenbloom, D.A. (2017). Defining and Understanding Pilot and Other Feasibility Studies. AJN The American Journal of Nursing, 117(3), 38-45, doi: 10.1097/ 01.NAJ.0000513261.75366.37.

14. Mutz, M., and Müller, J. (2016). Mental health benefits of outdoor adventures: Results from two pilot studies. Journal of Adolescence, 49, 105-114, https://doi.org/10.1016/ j.adolescence.2016.03.009.

15. Nowak, S. (1965). Studia z metodologii nauk społecznych. Warszawa: PWN.

16. Park, J., and Park, M. (2016). Qualitative versus Quantitative Research Methods: Discovery or Justification? Journal of Marketing Thought, 3(1), 1-7.

17. Thomas, G. (2017). How to Do Your Research Project: A Guide for Students. London: Sage.

18. Tonidandel, S., King, E.B., and Cortina J. (2016). Big Data Methods: Leveraging Modern Data Analytic Techniques to Build Organizational Science. Organizational Research Methods, 21(3), 525-547, DOI: 10.1177/1094428116677299.

19. Vaivio, J., \& Sirén, A. (2010) Insights into method triangulation and "paradigms" in interpretive management accounting research. Management Accounting Research, 21(2), 130-141, https://doi.org/10.1016/j.mar.2010.03.001.

20. Walliman, N. (2017). Research Methods: The Basics. London: Routledge.

21. Wilson, E.B. (1964). Wstęp do badań naukowych. Warszawa: PWN.

22. Zeigarnik, B.W. (1980). Patologia myślenia. Warszawa: PWN.

23. Zieleniewski, J. (1969). Organizacja i zarządzanie. Warszawa: PWN. 